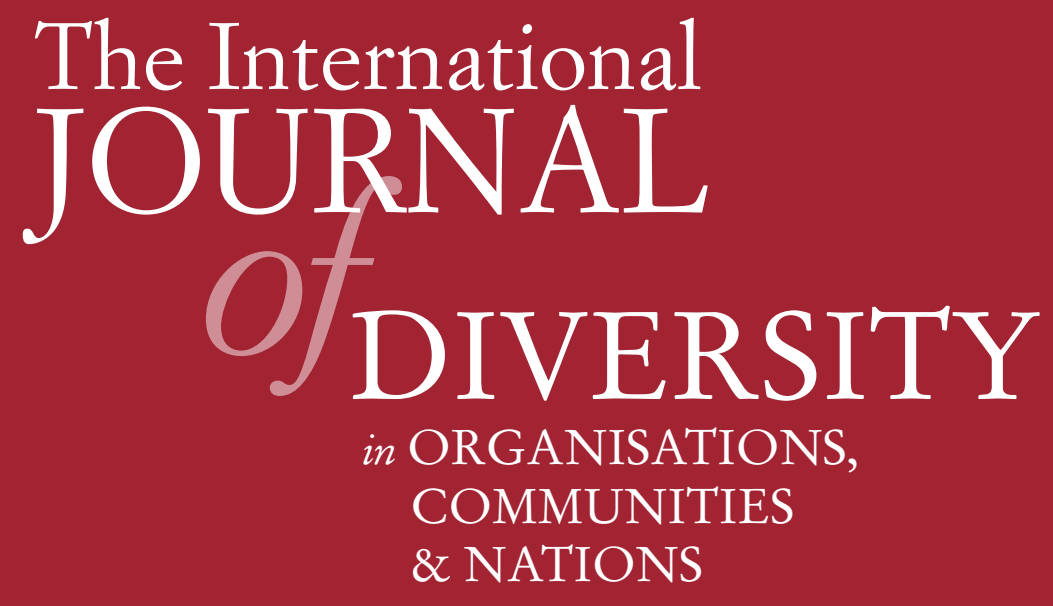

Volume 7, Number 6

Bumps on the Yellow Brick Road. Sierra Leoneans in Launceston, Australia and their Settlement Experiences

Ann Joselynn Sweeney 
THE INTERNATIONAL JOURNAL OF DIVERSITY IN ORGANISATIONS, COMMUNITIES AND NATIONS

http://www.Diversity-Journal.com

First published in 2008 in Melbourne, Australia by Common Ground Publishing Pty Ltd www.CommonGroundPublishing.com.

(C) 2008 (individual papers), the author(s)

(c) 2008 (selection and editorial matter) Common Ground

Authors are responsible for the accuracy of citations, quotations, diagrams, tables and maps.

All rights reserved. Apart from fair use for the purposes of study, research, criticism or review as permitted under the Copyright Act (Australia), no part of this work may be reproduced without written permission from the publisher. For permissions and other inquiries, please contact <cg-support@commongroundpublishing.com>.

ISSN: 1447-9532

Publisher Site: http://www.Diversity-Journal.com

THE INTERNATIONAL JOURNAL OF DIVERSITY IN ORGANISATIONS, COMMUNITIES AND

NATIONS is a peer refereed journal. Full papers submitted for publication are refereed by Associate Editors through anonymous referee processes.

Typeset in Common Ground Markup Language using CGCreator multichannel typesetting system http://www.CommonGroundSoftware.com. 


\title{
Bumps on the Yellow Brick Road. Sierra Leoneans in Launceston, Australia and their Settlement Experiences
}

\author{
Ann Joselynn Sweeney, University of Tasmania, Tasmania, Australia
}

\begin{abstract}
Australia has undeniably one of the best refugee settlement programs in the world (Refugee Council of Australia 2002). However, in the haste of designing and implementing these programs we often seek to generalise people's experiences in order to "get it right". Our government devotes millions of dollars to the "settlement plan" believing that success in settlement will deliver not only economic benefits to the country but integration into society. As a result, the story of settlement has been packaged and in packaging it much of what is important to the individual and to communities is missed. This study uses a community development action research approach to understand what settlement is from the point of view of a dynamic emerging community in Launceston, Tasmania - the Sierra Leoneans. This study suggests that success in settlement is dependent on experiences of quality and relevance in settlement services; marginalisation; racism; family conflict; gender issues; employment; and, connection to and participation with the local community. Further, that a successful settlement experience includes effective preparation before arrival in Australia; education of the local community; community capacity building; service delivery based on personal relationships; and, connection to the host community. In voicing the participants' settlement stories we seek to add to what is known about settlement. This study invites readers to question the necessity of packaging an experience that is said to be a life long journey to a very personal space of self determination, empowerment and freedom.
\end{abstract}

Keywords: Refugee Settlement

\section{Introduction}

\section{The Purpose of this Study}

$\mathrm{M}$

Y INTEREST IN the Sierra Leonean community comes from my work, observations and reflections of this emerging community within Launceston, a regional centre in the North of Tasmania, Australia where 92.4\% of the population are either born in Australia, England, New Zealand, Scotland, Netherlands or Germany (ABS 2006). I wondered why, as social workers, we implement and deliver services to a new emerging community despite our lack of mutual knowledge.

I felt the government's "settlement plan" restricted the meaning of settlement for the individual and thus for the community. It seemed to me that each time a person attempted to find employment, attempted to find private rental accommodation, went to English classes or accessed Torture and Trauma counselling their settlement experience was being measured against a pre-determined path that would identify them as a success or failure.

This success or failure is defined by The Department of Immigration and Citizenship (DIAC) (DIMIA 2003:29) as a "sink or swim" experience. The 'swim' occurs when people achieve self-sufficiency and the 'sink' when people become dependant on services to establish their life in Australia. I perceived this as an over-simplification of the settlement experience. To me, settlement appeared to be a very complex and individual journey.

As an involuntary migrant myself, I believe that there is no such pre-determined path to settlement; there is no hierarchy of needs; and, there is no end point to reach that completes the experience and declares it successful or otherwise. I believe there are many important practical needs associated with successful settlement but I wonder within whose frame of reference these are ranked.

This study is by no means "a means to an end". Rather, it is the beginning of a process of enquiry and evaluation that started with the voicing of my clients' settlement experiences. It is a personal journey of action learning, in which I am as much a facilitator of enquiry and action as I am a participant in the method of enquiry.

This project has taken a "bottom up" approach to community development action research, seeking to expose the myriad experiences that people have when they come to Launceston from Sierra Leone. It has invited all involved to reflect on their stories of settlement and it has supported and encouraged the community to build its capacity to determine and address its own agenda.

\section{THE INTERNATIONAL JOURNAL OF DIVERSITY IN ORGANISATIONS, COMMUNITIES AND NATIONS, VOLUME 7, NUMBER 6, 2008}




\section{The Sierra Leoneans}

Sierra Leone is a country located on the west coast of Africa, neighbouring Liberia and Guinea. It has a population of approximately 5.3 million people (BBC News 2006). English is the official language although the lingua franca is Krio (an English-based Creole) (CIA 2006).

Sierra Leone was ravaged by civil war between 1991-2002 resulting in tens of thousands of deaths and over 2 million displaced people (CIA 2006). Australia's offshore humanitarian program prioritised Africa in 2004, welcoming the first Sierra Leonean arrivals shortly thereafter (UNHCR 2004:3).

Differences among regions within Sierra Leone, as well as differences in religion contribute to the diversity that Sierra Leonean culture offers. However, underpinning Sierra Leonean culture are the collectivist values that underpin three fourths of the worlds' cultures (Leake \& Black 2005:18). Collectivism tends to view all aspects of life (including ideas) as interdependent; a person's identity is therefore based on one's roles and experiences within the larger group (Ibid). This view leads people to value group activity, cooperation, inclusion and social hierarchy based on age, gender and birth order (Ibid).

\section{The Refugee Experience}

Sierra Leoneans have experienced the worst kind of inhumanity imaginable: torture, rape, starvation and trauma (Samura 1999). Often people flee Sierra Leone with just the clothes they are wearing. The journey to camps in Guinea and Ghana is long, done on foot and riddled with uncertainty. People die of disease along the way and many turn back because of hunger or hopelessness of ever reaching a safe destination (Van Damme 1999).

Upon arrival at the camps, established by the United Nations and/or the International Organisation for Migration and/or Doctors without Borders, the suffering continues. Food is short, conflict continues, rape is daily and memories haunt. The wait for the United Nations High Commissioner for Refugees (UNHCR) registration process is long and paved with corruption and further humiliation (Odongkara 2005:3)

\section{What Happens Once they Arrive in Launceston?}

Humanitarian entrants undergo cultural orientation prior to leaving refugee camps as this is said to "enhance their settlement prospects" (UNHCR 2004:9). Accounts of settlement location (DIMIA 2005:51) point to the fact that no Sierra Leonean is given the opportunity to indicate where in Australia they prefer to settle. This is determined by DIAC.

On arrival in Launceston they are met by staff from the Migrant Resource Centre (MRC) whose duties include the delivery of the Integrated Humanitarian Settlement Strategy (IHSS) which allows for "individually tailored information, assistance and referrals to ensure [understanding] of the local community...social security, banking, education, employment, transport, childcare and other services" (UNHCR 2004:9). IHSS is aimed at introducing the person to mainstream services and self-sufficiency within six months after arrival (DIMIA 2003:163).

\section{Analysis of Research on Refugee Settlement Experiences in Australia}

The literature reviewed presents no consensus as to what constitutes successful settlement and how this could be measured. It does, by and large, assume that there is such a concept. This assumption is offered, in most cases, not by humanitarian entrants themselves but by professionals and bureaucrats. Thus, the ideas offered fail to recognise refugees as central stakeholders in the development of settlement policy and settlement services.

State and Federal government commissioned research on refugee settlement continues to be dominated by a belief that successful settlement can be defined and realised via a settlement plan. The successful achievement of "settlement" is generally identified on the basis of indicators that may include:

- employment rate;

- income levels;

- household expenditure;

- English language proficiency;

- quality of health;

- qualifications recognition;

- sponsorship of family relatives;

- satisfaction with life in Australia;

- inter-cultural interactions and networks; and,

- access to support services (Richardson et al 2004).

"The settlement experience of new migrants" by Richardson, Miller-Lewis, Ngo \& Ilsley (2002) concluded that humanitarian entrants' settlement outcomes are least favourable, in comparison to other categories of migrants, not because of service access and delivery failures but as a result of the personal disadvantages with which refugees arrive.

Ho and Alcorso (2004) argue that this is a reflection of the human capital approach to migration in Australia. That is, it is essentially an economic rationalist ideology that prevails in the design, development and delivery of migration policy. 
Community sector research challenges the rigid "plan and implement" approach preferred by government and seeks to incorporate the experiences of refugees into the analysis of settlement. However, the agenda of the research reviewed in this study remains a product of the researcher with refugee participation comprising merely a validation stage within the process of enquiry.

The Refugee Council of Australia (RCA) (2002, 2005 and 2006) suggests settlement is an "amorphous term" in the context of humanitarian entrants: a term for which one simple universal definition is elusive. However, although their reports do not provide one specific definition of settlement they do offer, as a guide for practitioners working with refugees, that the term settlement must not ignore the notion of empowerment. Furthermore, settlement is not a point to be reached but a process that will continue throughout the person's life.

It seems that many assumptions have been made by policy makers and non-government organisations in an effort to package the settlement experience and validate the design and delivery of a settlement plan. A gap in the literature is that we do not know if this plan is working for a community like the Sierra Leoneans. Furthermore, we do not know if the elements the literature suggests are being used as indicators of a "successful settlement experience" are, in fact, the elements that refugees focus on to achieve a successful experience.

One concludes that a participatory approach to research; one that facilitates notions of empowerment and process to feature prominently in analysis of settlement; is what is missing in the research reviewed. What is also missing is the notion that humanitarian entrants themselves can enact their own journey towards "successful settlement". There is no community development action research approach to enquiry in this area nor is there any suggestion made in the literature that such an approach would be welcomed by refugee communities.

\section{Methodology}

\section{Introduction}

The methods that we chose; and I say "we" because it was a collective decision of the Sierra Leonean community and myself; are framed in the belief that research is not merely a process of understanding the world by capturing people's experiences but it is also a chance to change and influence our human condition (Alston \& Bowles 1998:14). Underpinning our choice to conduct community development action research was the vision we share for social justice: a world that is capable of offering every human being equality, dignity and freedom.

\section{Choosing the Paradigm}

Ontologically, the participants and I believe that truth is revealed through people's stories. Epistemologically this truth is subjective, the product of our experiences. We believe that "social reality" is different to "reality" and that I, as facilitator, immersing myself in the realities of the participants as an observer and a participant can attempt to get "inside" their world as they define it (Cherry 1999:56). Once inside this world, I capture their descriptions, interpretations and explanations and together we reflect and act to change those realities that oppose our vision for social justice.

\section{My Role as Researcher}

My role was one of facilitator, a resource to assist the community in defining their issues and supporting them as they worked towards their solutions (Stringer 1996). My duty of care involved sitting comfortably and ethically with discomfort, acknowledging that not knowing means to trust that the process will reveal what needs to be known. Thus, it was important to engage in a constant process of critical self-reflection, to use a continual cycle of activities to test knowledge in action and to learn from each other.

\section{Cycle of Activities (Adapted from Cherry 1999)}

The methodology employed was adapted from Cherry's 'Action Research. A pathway to Action, Knowledge and Learning'(Cherry 1999). Features of the approach employed that were specific to this study included:

- the consultation of community elders in the planning and design phase to ensure community support and that a culturally appropriate interview approach was adopted;

- an approach to 'informed participation' that included the careful management of trauma recollection and the fears of participants about the potential consequences of any critical comments they may offer;

- an acknowledgement of the 'cultural entry' to the Sierra Leonean community made available to me and the implications of that entry for the reliability of the data;

- six semi-structured interviews conducted with four Sierra Leonean males and two Sierra Leonean females aged between 22 and 54 years;

- participants' responses during interviews were given context by processes of community reflection which occurred during gatherings, community events and celebrations; and, 
- cycles of shared reflections that both enhanced the validity of the research findings and offered two avenues for action viz. (a) design, development and implementation of a networking night held during Refugee Week that enabled more effective connections to be established between the Sierra Leonean and general community; and, (b) the collaborative design, development and facilitation (with two of the participants) of a cross-cultural workshop program Working on Genuine Self-Sufficiency.

\section{Is this Trustworthy Research? - Limitations to the Study}

So, is this study reliable and valid enough to be trusted and replicated by others in practice? To shed light on these issues I relied on concepts offered by Guba \& Lincoln (1981 \& 1982), Lincoln \& Guba (1985), Stringer (1999) and later expanded by Morse, Barnett, Mayan, Olsa \& Spiers (2002).

Credibility was established by the prolonged period of time spent with the Sierra Leonean community in the lead up to the study and during it. This long-standing engagement provided for the triangulation of the data collected during interviews and the checking and rechecking that stories of settlement were shared among community members.

We achieved transferability by testing the research findings during our actions and, as Eberhart and Pieper (1994) recommend listed exceptions to the findings so as to demonstrate that no single settlement story can be definitive.

\section{Results}

The results of this study are presented on the basis of the notion of settlement as a process with the analysis of data following the sequence that defined the interview schedule. A number of overarching themes will also be articulated in an attempt to synthesise effectively a more coherent expression of the nature of settlement than that adopted by the Australian government and associated agencies.

\section{Participant Profile}

The study involved six participants of whom four were male and two female with the youngest aged 22 and the oldest 54 . The group was evenly split between those of urban/professional and regional/agricultural backgrounds and similarly between those from the Mende and Krio ethnic groups. Three had roles as elders in their Launceston community. They had spent an average of six and a half years as refugees with two participants having endured this experience for more than nine years. While all parti- cipants came to Australia from camps in Ghana, four had reached Ghana via Liberia and two via Guinea.

\section{The Meaning of the Word Settlement}

Rather than imposing a meaning on participants, I chose to simply ask them what they thought the word settlement meant. It was variably described as a point at which life is lived normally, leaving the refugee experience behind; an opportunity to be free; to regain what was lost; a physical move to a place you have not experienced before; and an opportunity not to be 'differentiated' (participant \#2).

"It has so many significations, it has so many meanings but like settlement in general from my personal life is living...free" (participant \#1).

"Well in that sense it means...you've gained what you have lost..." (participant \#5).

\section{Is there a Beginning Point to Settlement?}

There was significant variance in participant responses to the question of when did settlement begin? For some, settlement began upon arrival in Australia. Others described a process of uncertainty, not knowing when and if settlement would ever take place: going through interviews, not hearing of outcomes and then realizing with a moments notice that the experience was theirs to have.

\section{Challenges Faced in Africa}

In stage two of the interview schedule conversations focused, with those who identified the settlement experience as commencing in Africa, on the challenges faced there and on who and/or what helped during this stage of the settlement experience. The challenges highlighted by participants were confronted while residing in refugee camps and included:

- food shortages \& associated diseases;

- no access to education, clean water, sanitation and/or medical care;

- no information given in relation to the processing of their application for refugee status or possibilities for re-settlement;

- no clear understanding of who was in charge and responsible for the management of the camps;

- discrimination and harassment by local Guineans and Ghanaians (countries of first asylum); and,

- trauma flashbacks.

Participants were unanimous in their view that the one element that helped during these times was personal drive, a desire to survive. No other agency or 
person was said to provide the necessary hope to face each day and get through to the next. The powerlessness felt during this time significantly influences the settlement experience by redefining safety in a manner that emphasises a need for a clear understanding of one's environment and the acquisition of the skills necessary to be self-sufficient in it.

\section{Expectations of Life in Launceston}

In stage three of the interview schedule, participants were asked about their priorities on arrival in Launceston. Participants related their expectations of life in Launceston which were, in all cases, closely aligned with their most pressing priority for settlement in Australia - continuing with their education:

\section{"My priority was to go to school...to continue my education for all of us, for me and my hus- band, for the kids...I thought as soon as we ar- rived in Australia I thought my kids would be in school" (participant \#4).}

Some were critical of the cultural orientation offered in Ghana as it presented them with the biggest challenge upon arrival in Launceston. Often, the information given at these orientation programs was of no relevance, contributing to fears and false expectations about life in Australia.

\section{The First Six Months after Arrival in Launceston}

In stage four of the interview schedule, participants were asked to explore whether or not their initial priorities had changed during the first six months after arrival. We delved into the challenges and assistance that was encountered and the positive aspects of these first six months of the settlement experience.

The initial priority of continuing education was again stated by all participants as being present during those first six months. A sense of being the only black people in Launceston, being stereotyped as primitive, uneducated and not exposed to Western lifestyles were also experiences related during interviews. Some expressed surprise at the host community's lack of knowledge of places like Sierra Leone. There were also comparisons drawn between life in Launceston and other Australian states. It seemed that by this stage some participants had either visited or heard of other Sierra Leoneans living in places like Perth and Melbourne:

"I think, you have maybe it's new receiving blacks you know. I don't know. I'm not trying to play the race card or whatever but it is the truth there weren't much blacks and people are much more, they are nice people and all in Tasmania and Launceston but we are dealing with people who are not much more freer than some communities in Melbourne where it is much more multicultural. There are many different cultures there and so people are used to living side by side whereas in Launceston it's a new phenomenon and it needs to be called and that's done through education..." (participant \#6).

The assistance received from the Migrant Resource Centre in Launceston was recognised by all participants. Further, help from individual volunteers was crucial in recognising cultural differences, developing their own networks of support, navigating the Australian welfare system and negotiating to realise their priorities upon arrival:

"That was [the volunteer help] one of the greatest things because this is a culture I don't understand, I've never been in this country and prior to that I was through so many traumatic situations and I'm coming to, expecting me to adjust myself to a culture that I'm not aware of, you know I don't have any networks or whatever..." (participant \#3).

Establishing daily routines, going to university, feeling safe and able to access opportunities were described as the most positive aspect of this early period. It is important to note here that the initial phase of settlement, seen by the government as the period when settlement is achieved is, in fact, a period when participants report having to deal with the tension between their expectations and reality. This, in turn, requires them to re-focus their priorities from the achievement of settlement to identifying the necessary pathway for their settlement journey.

\section{Feeling at Home in Launceston}

Stage five of the interview schedule focussed on the notion of feeling at home: what would it take for this to happen? If Launceston had become home, what did it take for that to occur?

The responses were largely dependent on whether or not people's priorities had been to some extent either explored or met in the time since the commencement of the settlement experience. For all participants, finding employment was associated with fitting into society as it provided a greater level of self-sufficiency and participants felt this enabled them to be an active member of society. This not only influenced the feeling of being at home but was also said to influence whether or not a participant felt settled. A sense of community was also described 
as contributing to a feeling of belonging in Launceston:

\begin{abstract}
"We came we heard too much Australian talk about community...but actually...there is people that only care about themselves. My type of community...sticks together...my problem is that when it comes to community building that is what hold us together. You talk about community here but I don't really see that" (participant \#3).
\end{abstract}

\section{Looking to the Future}

Stage six of the interview schedule invited participants to offer their views on issues that still required attention: issues that perhaps in the future would contribute to a positive and successful settlement experience. They were also invited to reflect on whether or not settlement actually could be a successful experience.

Settlement, it was unanimously agreed, can be a successful experience if the following can, over time, be addressed:

- flexibility in recognising qualifications and overseas work experience will make it possible to gain employment and reassert their identity;

- a recognition of the levels of non-verbal illiteracy present in the Sierra Leonean community and its implications for people's choices in accessing services, training, language development and healthcare;

- more relevant information at cultural orientations in Africa linked to and reinforced by information provided in Australia will lead to more realistic expectations of life in Australia and make it more possible to lay a solid foundation for settlement in the first six months after arrival;

- community building so that the community itself can assist those arriving and educate and prepare the host community which will, in the view of the participants, promote self-sufficiency, cultural exchange and reciprocal learning; and,

- friendships can be developed with those involved in refugee settlement in order to facilitate a feeling of connection with people - professional behaviour was said to contribute to feelings of disconnection and a sense of being engaged only in the context of professional duty:

“...They could not get everything done for us but if our networks are expanded we could get some of the things done for ourselves. We're not some kind of dependants, we're just trying to talk to those who know their way around you know, it's hard to do those things, it takes time, most things we get done...but friendships is hard to do with real people and I'm thinking Migrant [Resource Centre] they are supposed to be doing that." (participant \#6).

\section{Overarching Themes}

As the interviews were conducted as semi-structured conversations followed by shared reflections there were many comments offered, in addition to direct answers to the questions posed, that coalesced as themes. Here I propose to articulate the most commonly mentioned areas seen as influencing the settlement experience.

\section{Information}

Regardless of when the settlement experience commences, all participants identified that there is little information given to refugees to keep them at ease with the process of coming to Australia and to prepare them for the experience of the settlement process.

\section{The Refugee Experience}

All participants felt that life in a refugee camp offers no stability, safety or certainty - often the time spent there is years. Sharing these experiences with the host community and service providers was seen by participants as critical in deconstructing the myths they perceive to exist within the host community about refugee life and its effects on settlement in Australia. That is, the perceptions that many Australians have of Africans who are unable to use toilets and kitchen appliances or are generally unhygienic can significantly restrict the ability of a humanitarian entrant to access rental accommodation, be gainfully employed or be invited into local homes.

\section{Preparing for life in Australia}

Cultural orientations offered prior to arrival in Australia are often too simplistic; support false expectations of life in Australia; create fear; and, do not offer strategies for confronting cultural differences on arrival. These orientations are seen as missed opportunities to learn more about the Australian context. For example, many refugees learn that they will be provided with free permanent housing on arrival; that they will easily find work; and, that their arrival is eagerly anticipated by the host community.

\section{The aim of settlement}

Self-sufficiency was said to be the main aim of settlement. To achieve this aim, all participants commented on the need to also prepare the general com- 
munity for the arrival of humanitarian entrants to facilitate an atmosphere of welcome and mutual learning. Such an environment, it was said, would result in a greater sense of belonging for new arrivals and render it more likely that individuals and organisations in the host community would offer both moral and practical support in the settlement process.

\section{Summary}

The collection of varied definitions for settlement and the divergent and personal views about when settlement begins suggests that personal perspective is central to understanding the Sierra Leonean settlement experience. Further, for all participants, understanding the refugee experience as part of the process of re-settlement is critical to understanding the nature of settlement and the support that Sierra Leoneans would most benefit from once in Launceston.

Feeling at home in Launceston was said to largely depend on experiences of quality and relevance in settlement services; issues relating to marginalisation, racism, family conflict and gender issues; difficulties gaining employment and financial independence; and, opportunities for connection to and participation with the local community.

"I feel at home when I make connections and networks that I have built..." (participant \#3).

“...If I can get access to education I feel at home... [if I stop] worrying about getting job [I will feel at home]..." (participant \#1).

Successful settlement was identified as including effective preparation before arrival; education of the local community; service delivery based on personal relationships; and, connection to local community. Self-sufficiency was said to be the ultimate goal of settlement.

\section{Discussion and Recommendations}

\section{Introduction}

In drawing conclusions from a small-scale study like this one, one must acknowledge that these cannot claim to represent the totality of experiences shared by all Sierra Leoneans residing in Launceston (Okitikpi \& Aymer 2003). Claiming but one set of "truths" to rule out all others would be to incongruently sit with the paradigm which gave way to this enquiry.

Much of what is known about humanitarian settlement in Australia is based on defining, directing and quantifying the settlement experience via a settlement plan. Settlement has become an end in it self - a linear process with either a positive or negative out- come for those directly involved (DIMIA 2002, 2002 \& 2003, Richardson, Miller-Lewis, Ngo \& Ilsley 2002 and Richardson, Stack, Moskos, Lester, Healey, Miller-Lewis, Ilsley \& Harrocks 2004).

However, the findings of this study contest this understanding of settlement, reinforcing the importance of personal story telling and the need to not generalise what is described as a personal continuous journey to self-sufficiency (RCA 2002, 2005 \& 2006 $\&$ Klein 2000). A unique perspective has also emerged through this study: one that pertains to a sense of connection.

\section{Settlement}

The participants in this study support the view that the word settlement is a rather "amorphous term" (RCA 2002:4) carrying with it individual meaning and significance. The process of settlement, having a distinctive beginning and end point, can also be said to be an individual experience that defies generalisation.

Is there a set of "tangible markers" (RCA 2002) that guarantee success in settlement? It would appear that, for participants in this study, there are priorities that, if achieved, do offer a level of success. However, underpinning these priorities there is a human need to feel welcome and included in the country of settlement.

This study would suggest that although participants prioritised education, there were often other issues such as not being known; being stereotyped; confronting gender role differences; being rejected and excluded from the community; and, securing employment that also influenced the degree to which the achievement of settlement priorities contributed to a successful experience. This finding markedly challenges Richardson, Miller-Lewis, Ngo and Ilsley (2002) notion that personal disadvantages, brought from life in Africa, alone exert the greatest negative influence on the settlement experience of humanitarian entrants.

While participants did not suggest that the various tangible elements of the government's definition of settlement were invalid, they offered an alternative context within which to consider settlement. Things like employment, education, permanent housing, language proficiency and an understanding of Australian social mores are indeed seen as critical to the process of settlement. However, the notion of fixed term completion of that process was rejected as was the absence of important intangible factors in settlement such as welcoming and belonging: in other words, connection to the host community.

Profound issues that are often misinterpreted, or not known, by the general community were highlighted by participants including: 
- that the refugee experience did not guarantee that basic human right violations would cease to be experienced;

- that pre-arrival preparations did not complete people's understanding of Australian culture;

- that learning how to live in Australia is a process fraught with trial and error and dependant on time and consideration.

The ultimate goals that dominated participants' stories of settlement were empowerment and selfsufficiency; recognition of their skills; and, an acknowledgement of their experiences. This is in direct contradiction of the conventional government view yet seems to remain consistent with the accounts offered by the Refugee Council of Australia (2002), (2005) and (2006), Boyce and Madden (2000).

\section{Welcoming - Preparing for Connection}

Refugees have experienced pervasive, systematic oppression resulting in trauma (Aristotle 1999:5). Trauma leads to anxiety and a sense of loss of control arising from continuous periods of exposure to uncertainty (Ibid). Trauma also leaves individuals pondering whom to trust and forming new relationships is overwhelmingly difficult as previously held assumptions about what humans are capable of are shattered by memories of torture, rape, starvation and slavery (Pittaway 2004).

Refugees see the very worst of human nature and the shame and guilt felt at being the ones to survive is what leads most people to want to tell their story (Aristotle 1999). Offering a welcome and preparing ourselves to make that connection with survivors is the start of the healing process for refugees (RCA 2005, Ambikapathy 2003 \& Aristotle 1999).

\section{Concluding Reflections}

For Sierra Leoneans, coming to Australia represents a second or third attempt at re-establishing life (Odonogkara 2005). Although it is argued that prolonged geographical dislocation does not necessarily threaten people's capacity to feel at home in any one place, it is important for people to feel they belong (Barnes 2001:396). To belong implies the ability to be socially included (Ibid). Social inclusion, as the participants have stated, is dependant on having cultural, social and economic knowledge and having their experiences acknowledged and recognised. Participants in this study have specified that this is not yet part of their experience in Launceston.

In Tasmania we face one crucial challenge in offering emerging communities, such as the Sierra
Leoneans, a sense of social inclusion: we remain culturally homogeneous (Boyce \& Madden 2000:2) and this influences our ability to appreciate or be aware of what other cultures have to offer and what they need to feel included.

So, can we ensure that people who come from other cultures are ever settled and therefore feel at home in Australia? I do not propose that this study has offered a definitive answer to that question but I do offer that participants see themselves as different and, as much as they discuss learning and "ffitting in", there is an underlying assumption that the host community will also learn and adjust with them.

Barnes (2001) proposes that the longer refugees are marginalised, or excluded from the social context, the more different they will feel. The more different they appear, the more the dominant culture will see them as a threat to social cohesion (Ibid). The more they are seen as a threat, the more likely it is that the dominant culture will remain static, further reinforcing the challenges that newcomers are faced with upon arrival (Kibreab 1999:399).

This notion of a 'cycle of exclusion' is useful in considering the position expressed by participants in relation to the intangible human elements of settlement. I believe it is useful to view the settlement process as developing on a framework of tangible elements necessary for practical self-sufficiency in a new environment. However, it is important to acknowledge that the experiential elements that rest on this foundation are the connection with the host community that is so often problematic. Such a model and the removal of timeframes in government administration in relation to humanitarian entrants may well make effective settlement support more achievable.

This new home of ours, and I say ours because I feel connected to two homes and two cultures, offers an opportunity to experience "relations of inclusion and exclusion" (Olwig 1998:230). Rather than focusing exclusively on whether or not the "settlement plan" delivers new migrants' success or failure in settlement, I propose that the Sierra Leonean settlement experience invites us all to consider whether or not people's experiences are dominated by opportunities to connect or disconnect with their new home. If we are open to the proposition that people can feel at home anywhere, and whether or not they do depends on their experiences of connection or disconnection, than I believe we can link offers of compassion with limitless opportunities for connection and diversity wherever in the settlement journey we meet. 


\section{References}

Alinsky, S. (1971) Rules for Radicals. A Pragmatic Primer for Realistic Radicals. Vintage Books, Random House Inc. New York.

Alston, M. \& Bowles, W. (1998) Research for Social Workers. Allen \& Unwin, Crows Nest New South Wales.

Ambikapathy, P. (2003) Assisting traumatised migrant and refugee children and young people. Office of the Commissioner for Children Tasmania.

Argyris, C. (1991) “Teaching Smart People How to Learn”. Harvard Business Review. May-June, pages 99-109.

Aristotle, P. (1999) "Developing cultural responsiveness in the delivery of services to refugees and survivors of torture and trauma". Paper presented at the Restoration of victims of crime conference Melbourne.

Australian Association of Social Workers (1999) AASW Code of Ethics, $2^{\text {nd }}$ edn. Barton, ACT.

Australian Bureau of Statistics. (2006) 2006 QuickStats: Launceston (Tas) (Statistical District). <http:www.censusdata.abs.gov.au/ABSNavigation/prenav/LocationSearch> viewed 17/01/08.

Barnes, D. (2001) "Resettled Refugees' Attachment to their Original and Subsequent Homelands: Long-term Vietnamese Refugees in Australia". Journal of Refugees Studies. Volume 14. Number 4, pages 394-411.

BBC (2006) Country Profile Sierra Leone $<$ http://news.bbc.co.uk/2/hi/africa/country-profile/106156-5tm $>$ viewed 7 th October 2006.

Boyce, J. \& Madden, K. (2000) Promoting development of sustainable refugee communities in Tasmania. Social Action Research Centre. Anglicare Tasmania.

Brouwer, P. J. (1964) "The power to see ourselves". Harvard Business Review. November-December, pages: 36-46.

Central Intelligence Agency (CIA) (2006) The World Fact Book - Sierra Leone. $<$ http://www.odci.gov/cia/publications/factbook/index.html $>$ viewed $7^{\text {th }}$ October 2006.

Cherry, N. (1999) Action Research. A pathway to Action, Knoweldge and Learning. RMIT University Press, Melbourne.

Colic-Peisker, V. \& Tilbury, F. (2006) "Employment Niches for Recent Refugees: Segmented Labour Market in Twentyfirst century Australia”. Journal of Refugee Studies. Volume 19. Number 2, pages: 203- 229.

Connelly, F. M. \& Clandinin, D. J. (1990) "Stories of Experience and Narrative Inquiry". Educational Researcher. Volume 19. Number 5, pages: 2-14. <http://www.jstor.org> viewed $7^{\text {th }}$ October 2006.

Cornwall, A. \& Jewkes, R. (1995) “What is Participatory Research?”. Social Science and Medicine. Volume 41. Number 12, pages: 1667-1676. $<$ http://sitemaker.umich.edu/hps/files/cornwall and jewkes.pdf $>$ viewed $7^{\text {th }}$ October 2006.

“Cry Freetown" (1999) DVD recording, Freetown, Sierra Leone. Distributed by Insight News. Directed by Samuel Samura.

Department of Immigration, Multicultural and Indigenous Affairs (2002) "The Longitudinal Study of Immigrants". $<$ http://www.immi.gov.au/,edia/reserach/lsia/lsia02.htm> viewed $18^{\text {th }}$ November 2005.

Department of Immigration, Multicultural and Indigenous Affairs (2002) 'A 'client survey' on the effectiveness of DIMIA funded community settlement services" $<\mathrm{http}: / /$ www.immi.gov.au/research/projects/settlement/client survey.htm> viewed $18^{\text {th }}$ November 2005 .

Department of Immigration, Multicultural and Indigenous Affairs (2003) "Report of the review of settlement services for migrants and humanitarian entrants" May 2003. $<$ http://www.immi.gov.au/research/publications $>$ viewed $18^{\text {th }}$ November 2005.

Department of Immigration, Multicultural and Indigenous Affairs (2005) "Australia's support for Humanitarian Entrants 2004-2005". <http://www.immi.gov.au/research/publications> viewed $7^{\text {th }}$ October 2006.

Dunstan, S., Dibley, R. \& Shortland, P. (2004) "Refugee Voices: A Journey Towards Resettlement. New Zealand Immigration Service”. Departments of Labour. $<$ http://www.immigration.gov.nz $>$ viewed $18^{\text {th }}$ November 2005.

Eberhart, C. \& Pieper, B. (1994) "Understanding human action through narrative expression and hermeneutic inquiry". In Chinn, P. (Ed) Advances in Methods of Inquiry for Nursing (pages: 41-58).. Bathesda, Aspen.

Freire, P. (1972) Pedagogy of the Oppressed. Penguin, Harmondsworth.

Guba, E. G., \& Lincoln, Y. S. (1981) Effective evaluation: Improving the usefulness of evaluation results through responsive and naturalistic approaches. Jossey-Bass. San Francisco, California.

Guba, E. G., Lincoln, Y. S. (1982) "Epistemological and methodological bases of naturalistic inquiry”. Educational Communication and Technology Journal. Volume 30. Number 4, pages: 233-252.

Guba, E. G., \& Lincoln, Y. S. (1989) Fourth Generation Evaluation. Sage. Newbury Park, California.

Ho, C. \& Alcorso, C. (2004) "Migrants and employment. Challenging the success story" Journal of Sociology. Volume 40. Issue 3, pages: 237-259.

Hycner, R.H. (1985) "Some guidelines for the phenomenological analysis of interview data". Human Studies. Volume 8. Number 3, pages: 279-303.

Ife, J. (2002) Community Development. Community-based alternatives in an age of Globalisation. Pearson Education, Australia.

Kenny, S. (1999). Developing Communities for the Future. Community Development in Australia. Thomson. Victoria, Australia.

Kibreab, G. (1999) "Revisiting the Debate on People, Place, Identity and Displacement". Journal of Refugee Studies. Volume 12. Number 4, pages: 384-410.

Klein, T. (2000) "The settlement experiences of people from Ethiopia in Sydney and Melbourne"

Kyle, L., Macdonald, F., Doughney, J. \& Pyke, J. (2004) "Refugees in the Labour market. Looking for cost-effective models of assistance” Ecumenical Migration Centre Brotherhood of St Laurence. $<$ http://www.bs1.org.au/pdfs/refugees_in_labour_market.pdf $>$ viewed $18^{\text {th }}$ November 2005. 
Leake, D. \& Black, R. (2005) “Essential Tools. Improving Secondary Education and Transition for Youth with Disabilities. Cultural and Linguistic Diversity: Implications for Transition Personnel”. Institute on Community Integration, University of Minnesota, Minneapolis. $<$ http://www.ncset.org/publications/essentialtools/diversity/EssentialTools_Diveristy.pdf $>$ viewed $29^{\text {th }}$ September 2006.

Lincoln, Y. S. \& Guba, E. G. (1985) Naturalistic Inquiry. Sage. Beverly Hills, California.

Lindsey, E. \& McGuinness, L. (1998) "Significant elements of community involvement in participatory action research: evidence from a community project". Journal of Advanced Nursing. Volume 28. Number 5, pages: 1106-1114.

McNiff, J. (1988) Action Research Principles and Practice. Routledge, New York.

Migrant Resource Centre (Northern Tasmania) Inc. (2005) Annual Report.

Migrant Resource Centre (Northern Tasmania) Inc. (2006) Annual Report.

Morse, J. M., Barrett, M., Mayan, M., Olson, K. \& Spiers, J. (2002) "Verification Strategies for Establishing Reliability and Validity in Qualitative Research". International Journal of Qualitative Methods. Volume 1. Number 2, pages: 1-19.

Mullaly, B. (2002). Challenging Oppression. A Critical Social Work Apporoach. Oxford University Press. Ontario.

Nightingale, D. \& Cromby, J. (Eds) (1999) Social constructionist psychology. Open University Press, Buckingham. <http:// www.psy.dmu.ac.uk/michael/qua reflexivity.htm> viewed 29th September 2006.

Odongkara, J. A. (2005) “Unique Vision, Shared Strengths: Collaborative approach to African Humanitarian Migrants' issues; Western Australia". Ethnic Communities Council of WA Inc. Paper presented at "Refugee Conference" University of New South Wales. <http://www.crr.unsw.edu.au/documents $>$ viewed $7^{\text {th }}$ October 2006.

Okitikpi, T. \& Aymer, C. (2003) "Social Work with African Refugee Children and their families". Child and Family Social Work. Volume 8, pages: 213-222.

Olwig, K. F. (1998) “Contested Homes: Home-making and the Making of Anthropology”. In Rapport, N. and Dawson, A. (Eds) Migrants of Identity: Perceptions of Home in a World of Movement. Oxford: Berg.

Organisation of African Unity (1969) Convention Governing The Specific Aspects of Refugee problems in Africa. $<$ http://www.africa_union.org/refugee-convention.pdf $>$ viewed $9^{\text {th }}$ October 2006.

Pittaway, E. (2004) The Ultimate Betrayal: An Examination of Domestic and Family Violence in Refugee Communities. Centre for Refugee Research, University of New South Wales.

Ploeg, J. (1999) "Identifying the best research design to fit the question. Part 2: qualitative designs". Evidence Based Nursing. Volume 2, pages: 36-37. <http://www.ebn.bmjjournals.com> viewed $7^{\text {th }}$ October 2006.

Porteous, S. (2004) "Access to mainstream services by culturally and linguistically diverse communities in Manningham, Whitehorse \& Knox” Migrant Resource Centre Eastern Melbourne. <http://www.miceastmelb.com.au/documents/accessservices $>$ viewed $12^{\text {th }}$ April 2006.

Refugee Council of Australia (2002) "Submission to the Minister for Citizenship and Multicultural Affairs in the context of the review of settlement services for migrants and humanitarian program entrants" $<$ http://www.refugeecouncil.org.au/docs/current_issues/2002_settlement_services_reviewpdf viewed 18th November 2005.

Refugee Council of Australia (2005) "Australia's refugee and Special Humanitarian Program: Current Issues and Future Directions". Views from the Community Sector. February 2005. <http://www.refugeecouncil.org.au/docs/current_issues $>$ viewed $18^{\text {th }}$ November 2005.

Refugee Council of Australia (2005) "Australian Mentoring Programs for Refugee and Humanitarian Entrants”. May 2005. <http://www.refugeecouncil.org.au/docs/current_issues $>$ viewed $9^{\text {th }}$ October 2006.

Refugee Council of Australia (2006) "Australia's refugee and Special Humanitarian Program: Current Issues and Future Directions”. Views from the Community Sector. February 2006. $<$ http://www.refugeecouncil.org.au/docs/current_issues $>$ viewed $29^{\text {th }}$ September 2006.

Richardson, S., Miller-Lewis L., Ngo P. \& Ilsley D. (2002) "The settlement experiences of new migrants. A comparison of wave one of LSIA 1 \& 2". Department of Immigration, Multicultural and Indigenous Affairs. $<\mathrm{ht}-$ tp://www.immi.gov.au/research/publications> viewed 18th November 2005.

Richardson, S., Stack, S., Moskos, M., Lester, L., Healey, J., Miller-Lewis, L,. Ilsley, D. \& Harrocks, J. (2004) "The Changing Settlement Experience of New Migrants. Inter-wave comparisons for Cohort 1 \& 2 of the LSIA”. Department of Immigration, Multicultural and Indigenous Affairs. $<$ http://www.immi.gov.au/research/publications $>$ viewed 18th November 2005.

Ryan, T. (2005) "Reflexivity and The Reader: An Illumination". The Ontario Action Researcher. Nipissing University, North Bay. $<$ http://www.nipissingu.ca/oar/PDFS/V72.pdf $>$ viewed $7^{\text {th }}$ October 2006.

Small, S. A. (1995) "Action Oriented Research: Models and Methods". Journal of Marriage and the Family. Volume 57. Number 4, pages: 941-955. <http://www.jstor.org> viewed $7^{\text {th }}$ October 2006.

Stringer, E. T. (1996) Action Research. A handbook for practitioners. Sage Publications, California, U.S.A.

Stringer, E. T. (1999) Action Research. Second Edition. Sage Publications, California, U.S.A.

Tasmanian State Government (2000) "Submissions to consultations on the 2000-2001 migration and humanitarian program". February, 2000.

United Nations Refugee Agency (UN High Commissioner for Refugees) (2004) "Resettlement Handbook: country chapter Australia" $<$ http://www.unhcr.org $>$ viewed $7^{\text {th }}$ October 2006.

Van Damme, W. (1999) "How Liberian and Sierra Leonean Refugees settled in the forest region of Guinea 1990-96". Journal of Refugee Studies. Volume 12. Number 1, pages: 36-53. 


\section{About the Author}

Ann Joselynn Sweeney

I am a social worker working with African Refugee communities in Launceston. Bumps on the Yellow Brick Road was my honours thesis project in social work. Some of the participants of this research and I also run cultural awareness workshops for Human Services in Tasmania and more recently for University staff and academics. As an involuntary migrant my self I have dedicated my work to culture and community and it is my hope to submitt this paper in an effort to voice refugee settlement stories internationally. 



\section{THE INTERNATIONAL JOURNAL OF DIVERSITY IN ORGANISATIONS, COMMUNITIES AND NATIONS}

\section{EDITORS}

Mary Kalantzis, University of Illinois, Urbana-Champaign, USA.

Paul James, RMIT University, Australia

\section{EDITORIAL ADVISORY BOARD}

Ien Ang, University of Western Sydney, Australia.

Samuel Aroni, University of California, Los Angeles, USA.

Duane Champagne, University of California, Los Angeles, USA.

Guosheng Y. Chen, RMIT University, Melbourne, Australia.

Jock Collins, University of Technology, Sydney, Australia.

Bill Cope, University of Illinois, Urbana-Champaign, USA.

Heather Marion D'Cruz, Deakin University, Geelong, Australia.

James Early, Smithsonian Institution, Washington, DC, USA.

Denise Egéa-Kuehne, Louisiana State University, Baton Rouge, USA.

Amareswar Galla, Australian National University, Canberra, Australia.

Barry Gills, University of Newcastle, UK.

Jackie Huggins, University of Queensland, Australia.

Andrew Jakubowicz, University of Technology, Sydney, Australia.

Ha Jingxiong, Central University of Nationalities, Beijing, China.

Peter McLaren, University of California, Los Angeles, USA.

Joe Melcher, Xavier University of Louisiana, New Orleans, USA.

Greg Meyjes, Solidaris Intercultural Services L.L.C, Falls Church, VA, USA.

Walter Mignolo, Duke University, USA.

Brendan O'Leary, University of Pennsylvania, USA.

Aihwa Ong, University of California, Berkeley, USA.

Peter Phipps, RMIT University, Melbourne, Australia.

Ronald Prins, Managing Director, Bos en Lommer Neighbourhood Council, The Netherlands.

Peter Sellars, Theatre, Opera and Film Director.

Michael Shapiro, University of Hawai'i, USA.

David S. Silverman, Valley City State University, North Dakota, USA.

Martijn F.E. Stegge, Diversity Platform, City of Amsterdam, The Netherlands.

Geoff Stokes, Institute for Citizenship and Globalisation, Deakin University, Melbourne, Australia.

Terry Threadgold, Cardiff University, Wales, UK.

Mililani Trask, Indigenous Expert to the Permanent Forum on Indigenous Issues for the Economic Council of the UN Assembly, Hawai'i, USA.

Marij Urlings, Dean, School of Health Inholland University, Amsterdam-Diemen, The Netherlands.

Joanna van Antwerpen, Director, Research and Statistics, City of Amsterdam, The Netherlands.

Grethe van Geffen, Seba Cultuurmanagement, Amsterdam, The Netherlands.

Rob Walker, Keele University, UK.

Ning Wang, Tsinghua University, Beijing, China.

Owens Wiwa, African Environmental and Human Development Agency, Toronto, Canada.

Please visit the Journal website at http://www.Diversity-Journal.com for further information:

- $\quad$ ABOUT the Journal including Scope and Concerns, Editors, Advisory Board, Associate Editors and Journal Profile

- $\quad$ FOR AUthORs including Publishing Policy, Submission Guidelines, Peer Review Process and Publishing Agreement

SUBSCRIPTIONS

The Journal offers individual and institutional subscriptions. For further information please visit http://ijd.cgpublisher.com/subscriptions.html. Inquiries can be directed to subscriptions@commongroundpublishing.com

INQUIRIES

Email: cg-support@commongroundpublishing.com 